lime; if there be more than sufficient to satisfy all the lime, the remainder is calculated to carbonate of magnesia; if there be too little, however, the remaining lime is combined with sulphuric acid ; any remaining sulphuric acid is calculated to sulphate of magnesia, and so on ; the order in which the bases and acids are taken being therefore as follows :-

\begin{tabular}{l|l} 
Lime, & Magnesia, \\
Soda. & $\begin{array}{l}\text { Carbonic acid, } \\
\text { Sulphuric acid, } \\
\text { Nitric acid, } \\
\text { Hydrochloric acid. }\end{array}$
\end{tabular}

Now, although this is the usually accepted and conventional method of returning an analysis, there is no doubt that the assumptions it involves are altogether arbitrary, illegitimate, and unscientific. The only scientific method of returning a water analysis is to represent (in parts per 100,000; not in grains per gallon, as the atrocious English system of weights and measures generally compels us to) the constituents actually found; as, for instance,

$\mathrm{CaO} ; \mathrm{MgO} ; \mathrm{CO}_{2} ; \mathrm{N}_{2} \mathrm{O}_{5} ; \mathrm{Cl}$; \&c.

This is all that an analyst is entitled to say, and this much is certain : when we proceed to combine the constituents, we are dealing in conjecture.

Unfortunately, however, it seems to be a "law of Nature" that those classes of the community who chiefly require the services of analysts are absolutely ignorant of the merest rudiments of chemistry; the consequence is that if any analytical purist endeavours to reform upon the conventionally established procedure, and to return a certificate of analysis in a scientific manner, his clients are up in arms at once, and indignantly demand what he means by sending them such a nonsensical rigmarole.

Thus far, then, we are helpless; but it is most undesirable that this conventional procedure should be adhered to whenever it is possible to substitute the scientific (as in an analysis of purely scientific interest).

"R. B. H. " asks what salts really exist in solution.

According to Ostwald and others, no salts at all if the solution be dilute enough, but only dissociated ions with electrical charges. But whether this theory be correct or not, it is improbable to the last degree that an analysis represents the salts actually present. The indeterminateness of the problem is clearly shown by the fact that from the same solution either sodium chloride and magnesium sulphate, or sodium sulphate and magnesium chloride, may be obtained, according to the method of crystallization adopted. Even supposing that Ostwald's theory be incorrect, and that not ions but salts exist in solution, and that these different results be due to double decomposition occurring in one case, it would be a gigantic assumption that we can definitely show the exact natural distribution in a complicated solution containing eight or ten constituents.

If " R. B. H." wishes to see an account of how acids and bases distribute themselves in a simple solution, he may consult Ostwald's "Outlines".(p. 338, \&c., English translation), and also the discussion on avidity in Lothair Meyer's "Modern Theories of Chemistry" $(472-87)$. F. H. PERRY COSTE,

7 Fowkes Buildings, Great Tower St., E. C., Nov, 28.

I AM much indebted to Mr. Perry Coste for his clear and candid answer to my question. It is exactly the answer which I anticipated. The actual facts established by analysis are too often forced, by the arbitrary assumptions of the analytical chemist, to yield unwarrantable conclusions.

The reason given is, that "the people love to have it so." I had hoped that chemists could give some better grounds for their proceedings. They bring to mind the words of the old prophet: "A wonderful and horrible thing is come to pass in the land ; the prophets prophesy falsely," . . . for "my people love to have it so ; and what will ye do in the end thereof?" Surely we may henceforth claim, in the interests of truth or (which is the same thing) science, that chemists will give us in every case the actual facts obtained by analysis; and if they proceed further for the sake of the prejudices of the ignorant, they will at least warn them that such further inferences are not trustworthy, and have only a very moderate amount of probability, if they can even lay claim to any probability at all.

I speak feelingly, because I have had occasion to examine a great number of analyses of water from the chalk of the London Basin, telling me, in most cases with a " cocksureness" which has amazed me, what salts, and what amount of them, these waters contained, and these, for purposes of comparison, I have had painfully to reduce back to the real facts from which they were derived.

I am quite prepared to believe that the investigations of Ostwald and others as to solutions show that salts as such do not exist in these waters at all, and that the relations of acids and bases in such cases are variable with the physical condition of the water. As an instance which has come under my own notice, it was reported by competent chemists, with reference to water from a deep well in Harrow, in which an unusual quantity of magnesium and sulphuric $\cdot$ acid was found, that at $60^{\circ} \mathrm{F}$. its hardness was $10^{\circ} .4$ (grs. per gall.); that, mixed with an equal quantity of distilled water, its hardness rose to $24^{\circ}$ : while at the temperature of $158^{\circ}$ it rose to $26^{\circ} \cdot 5$. I suppose that a chemist would hardly attempt to assign with much confidence what exact changes in the relations of the dissolved constituents would produce these and similar results. All the more reason, then, why analysts should limit themselves to statements which they can vouch for by direct observation and the balance.

My remarks having extended beyond a mere question, I think it best to sign myself in full,

ROBERT B. HAXWARD.

\section{Peculiar Eyes.}

Mr. SHAw's case is by no means so peculiar as he supposes I imagine that everyone who has had to do with experimental questions of physiological or psychological optics has found it to be rather the exception than the rule that an investigation of his reagents' eyes has shown their perfect equality-as regards "long" and "short" sight, colour sensitivity, and sensitivity to light. The common preferential use of one eye explains a good deal (cf., e.g., Aubert, "Physiol. d. Netzhaut," p. 18; Schön, Arch. f. Ophthalmologie, xx. 2, p. 27r). Mr. Shaw may also be colour-blind in one eye ; the perception of colour difference alone is no criterion. I find it safest to employ the wool, spectrum, and coloured-card tests in combination.

Animals (with the exception of the very highest) have normally a so restricted binocular vision that they need not be taken into account.

It may be interesting to note that a like difference of sensa. tional capacity exists between the two ears. A tuning-fork held to one ear may, quite normally, drown a tone-sensation which is half a musical tone deeper or higher than that excited by the same fork in the other ear. E. B. TITCHENER. I P.S. - I discovered the very considerable inequality of my own eyes quite accidentally in my sixteenth year.

\section{Alleged Pseudopodes of Diatoms.}

WiLI you allow me to express my concurrence in your criticism (p. 140) on Mr. Grenfell's paper on the occurrence of pseudopodia in the Diatomaceous genera Melosira and Cyclo. tella? I express no doubt on the accuracy of Mr. Grenfell's observations, the knowledge of which I have derived from his paper in the Quarterly Fournal of Microscopical Science, anil from his verbal description at a meeting of the Linnean Society ; but $I$ do desire to enter my protest against the use of the term "pseudopodia" for the protoplasmic filaments observed by him. According to the accepted meaning of this term, it is applied to masses of protoplasm which are in organic connection with the protoplasm of the body of the organism, and which are retractile. I understand $\mathrm{Mr}$. Grenfell that he is unable to affirm either of these facts with regard to the structures observed by him ; and, until this is done, the application to them of the term "pseudopodia" appears to me to involve a begging of the question at issue, and a needless and regrettable confusion in terminology. AlFRed W. BenNetT.

\section{Intelligence in Birds.}

UNDER this head Mr. Wilkins, in your last impression (p. I5 I), speaks of Pocioces pancri hiding food in the sand. I have a fox-terrier puppy which was taken from its mother when about seven weeks old, and sent to me. I have no other dogs, nor has he seen any dogs, but he buries bones in the garden with great skill, digging a hole with his fore-paws. $\mathrm{He}$ puts in the bone, and carefully pushes it down with his nose, and then covers it with garden soil, which is pushed in with his nose. The work is very carefully and elaborately well done.

I have had, at various times, very many dogs of all kinds and ages, but I never saw so young a puppy bury bones, or any dog do it so well. It is an admirable example of pure heredity.

Norfolk Street December I9.
JOE.

NO. I I 56 , VOL. 45$]$ 